\title{
Ladan and Laleh
}

The two of you never knew the necessary interludes, the take leave from the presence of others delectable silences, once the heart is sated. Projected from the birth canal into each other's orbit two heads yoked together, like the ring belongs to Saturn your entwined anatomies dictated no reprieve.

The singular pleasures, evening walks, morning ablutions, unnoticed by most of us, became for you dreaded gymnastics; an impossible calculus of muscle, flesh and bone movement. At night your private islands, dreamlets disrupted anticipating another's arm fling, leg thrust or head turn. Yet you shared, evolved and taught us the genius of accommodation.

Until one day the razor of instinct sensing a cure, an opportunity, the now or never timing to trust the cunning of the scalpel, made you consult the neurologist, that specialist of the forlorn. Could he, you asked, separate the common vessel along the desire lines of each other's personal azimuth?

Growing into excitement for a defining contour, here, there, brushstrokes to create an individual topography of manner and gesture, made you risk death on the operating theatre. That night you dreamed you were a tall riverbank tree, gazing at your sister on the other side, your separate roots tapping into the flowing river of eternity underneath.

For three days and three nights, the world held its breath while surgeons spliced and cleaved the anesthetized cohesion but sadly, the conjoined vessels would not yield the sculpted identities you yearned for.

Now the world retracts into its shell.

In our houses we continue to hide all day, crushed beneath the inertia of loneliness. With you no longer with us,

$\underset{\sim}{\infty}$ a peece of the shore ${ }^{1}$ has washed away,

"La rose qui pleure, séparée de son rosier."*

\section{Normand Carrey MD}

Psychiatrist

IWK Health Centre

Halifax, NS

\footnotetext{
* "The rose that weeps, separated from its rosebush."
}

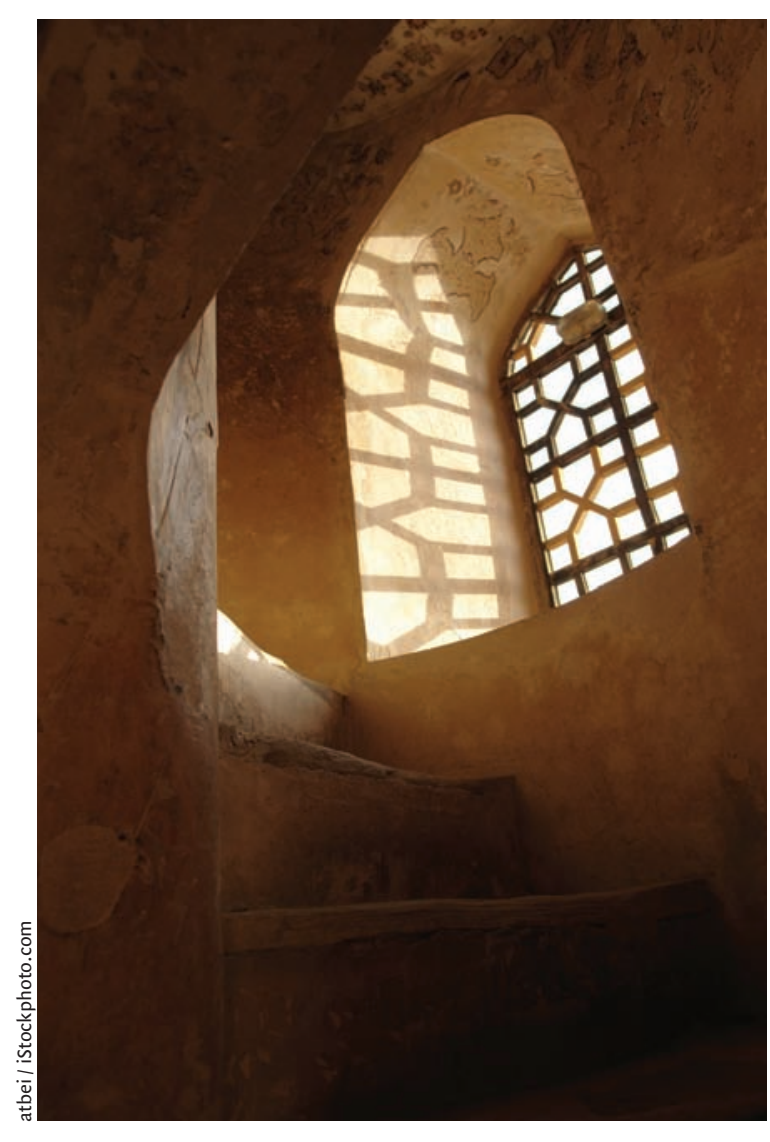

\section{REFERENCE}

I. Donne J. Devotions upon emerging occasions. New York: Oxford University Press; I987. p. 87

"Ladan and Laleh" concerns the famous Iranian conjoined twins who died during the surgery to separate them. The tragedy caused an outpouring of grief in their native Iran. 